\title{
Aspectos da pesquisa colaborativa na formação docente
}

\section{Denise Moreira Gasparotto* Renilson José Menegassi**}

\section{Resumo}

Este trabalho discute o conceito de pesquisa colaborativa no campo aplicado dos estudos de linguagem escrita, a partir de pesquisas brasileiras sobre o tema (MAGALHÃES, 1994, 1998, 2002; MAGALHÃES; FIDALGO, 2010; IBIAPINA, 2008; CABRAL, 2012; HORIKAWA, 2008; BORTONI-RICARDO, 2011). Objetivamos compreender e sistematizar as caraterísticas dessa abordagem de pesquisa e as etapas que a compõem. A partir de pesquisa colaborativa realizada com uma docente de Língua Portuguesa, acerca dos processos de revisão e reescrita, pautada nos pressupostos dialógico (BAKHTIN, 2010), analisamos a aplicação prática das características e etapas levantadas, apresentando alternativas para o desenvolvimento de um trabalho colaborativo. Os resultados apontaram a importância dessa abordagem de pesquisa para a formação de professores e para os processos de ensino-aprendizagem, destacando o engendramento necessário entre academia, escola, teoria, metodologia, prática, sujeito e contexto, na orientação de pesquisas de caráter teóricometodológico.

Palavras-chave: Pesquisa colaborativa. Formação docente. Revisão e reescrita.

\footnotetext{
* Mestre e Doutoranda em Letras na Universidade Estadual de Maringá (UEM). Professora do Instituto Federal Catarinense (IFC), Campus Videira.

*** Doutor em Letras pela Universidade Estadual Paulista Júlio de Mesquita Filho (UNESP). Professor do Departamento de Letras e do Programa de Pós-Graduação em Letras na Universidade Estadual de Maringá (UEM).
} 


\section{Considerações iniciais}

As pesquisas no campo aplicado dos estudos da linguagem escrita têm, dentre seus muitos pressupostos epistemológicos, o objetivo de atrelar as teorias de linguagem às práticas de ensino. Assim, grande parte delas se insere na modalidade qualitativa de pesquisa, pelo viés do interpretacionismo (LUDKE; ANDRÉ, 1986; ANDRÉ, 1995, 1997, 2000). A pesquisa qualitativa tem várias ramificações, cada qual visando a um objetivo específico, dentre elas destacam-se a etnografia, a pesquisa-ação, o estudo de caso e a pesquisa colaborativa.

Este trabalho ${ }^{1}$ enfoca a pesquisa colaborativa, abordagem que vem apresentando resultados significativos no tocante à formação continuada de professores e ao ensino-aprendizagem. Na busca por aprimorar os mecanismos de entrada do pesquisador no ambiente escolar, a pesquisa colaborativa visa à intersecção entre academia e escola no sentido de promover conhecimento, autoavaliação e construção de novas práticas, por meio da ação e da reflexão (BORTONI-RICARDO, 2011), que conduzam à produção de metodologias próprias de trabalho, sustentadas por escopo teóricometodológico adequado. Em vez de o pesquisador inserir-se no ambiente escolar apenas para observar, dizer o que está ou não adequado, objetiva-se discutir junto ao professor a realidade de seu trabalho, as dificuldades encontradas e oferecer subsídios teórico-metodológicos para a implementação de novas práticas que ressignifiquem seu trabalho. Trata-se, portanto, de uma proposta de pesquisa em que todo o processo é conduzido em coparticipação entre professor e pesquisador, visando sempre à reestruturação e reconstrução do trabalho com a linguagem em situação de ensino, no caso específico deste estudo, dos aspectos relacionados à revisão e à reescrita de textos.

Para tanto, buscam-se discussões de pesquisadores brasileiros acerca da pesquisa colaborativa, organizando de maneira didática os aspectos que caracterizam essa modalidade de pesquisa e as etapas que compõem esse processo. Após levantamento teórico, relata-se uma experiência de pesquisa colaborativa, constituída em uma perspectiva dialógica de discurso (BAKHTIN, 2010), realizada com uma docente de Língua Portuguesa acerca dos processos de revisão e reescrita textual, com seus alunos de $4^{\circ}$ e de $5^{\circ}$ anos do Ensino Fundamental em um município do Noroeste do Paraná, no período de julho a dezembro de 2012. A experiência é relatada a partir das fases da pesquisa colaborativa sistematizadas e propostas por Bortoni-Ricardo (2011), o que permite confirmar aspectos essenciais ao bom desenvolvimento da colaboração, assim como oferecer alternativas de trabalho aos pesquisadores que almejam aventurar-se nessa complexa e valorosa modalidade de pesquisa, que se mostra como uma 
das possibilidades para diminuir as diferenças entre o que se produz na academia e o que se pratica na escola.

\section{A pesquisa colaborativa}

A pesquisa colaborativa, ancorada nas bases da pesquisa qualitativa, apresenta aproximações com a etnografia em ambiente escolar e vem sendo ricamente utilizada no sentido de ampliar a participação do pesquisador na escola. Seu objetivo maior atende à necessidade de estreitar laços entre escola e academia, promovendo resultados profícuos relacionados diretamente à prática docente, “contribuindo para a elaboração de novas compreensões acerca dos trabalhos realizados na instituição escolar, estabelecendo um compromisso da academia de também se engajar na busca das soluções para as problemáticas aí apresentadas" (HORIKAWA, 2008, p. 27).

Sabe-se que a entrada do pesquisador na escola nem sempre é bem aceita pela comunidade escolar. Muitas vezes, ele é visto como aquele que observa unicamente para avaliar, sem oferecer contribuições à realidade encontrada. A partir dessa discussão, Bortoni-Ricardo (2011) destaca que, em uma pesquisa qualitativa etnográfica, o desenvolvimento do trabalho colaborativo contribui para a formação do professor e para a transformação da realidade por meio da ação e da reflexão.

A pesquisa colaborativa no âmbito escolar é um trabalho coparticipativo de interação entre pesquisador externo e professor ou grupo de professores, num processo de estudo teórico-prático que envolve constante questionamento e teorização sobre as práticas e teorias que norteiam o trabalho docente (BORTONI-RICARDO, 2011), no sentido de compreender a realidade e construir novas ações que contribuam para melhor desenvolvimento do ensino. Dessa forma, toda a pesquisa é produzida com o professor e não para ele, o que é o grande diferencial. O pesquisador tem na realidade estudada o seu objeto de investigação, podendo construir conhecimento com base nesse contexto, descrevendo, explicando e também intervindo nele. Além de Bortoni-Ricardo (2011) e Horikawa (2008), outros autores como Magalhães (1998, 2002), Magalhães e Fidalgo (2010) e Ibiapina (2008) defendem a pesquisa colaborativa, destacando a construção coletiva do conhecimento e intervenção sobre a realidade estudada como suas principais características.

Magalhães e Fidalgo (2010) explicam que a colaboração é um processo compartilhado de avaliação e reorganização de práticas, incluindo-se os aspectos metodológicos, no qual se criam contextos abertos para que todos os participantes falem, questionem, relatem etc. Assim, as 
divergências de opiniões, valores, ideias são aspectos favoráveis, pois a crítica é tida como ferramenta para a construção de novos conhecimentos. Ela não é vista negativamente e esse é um dos grandes desafios à implementação da pesquisa colaborativa. Ancoradas em John-Steiner (2000), as autoras salientam que a problematização sobre práticas já estabelecidas não é comumente bem-vista no ambiente escolar e pode levar à compreensão de que o conhecimento já adquirido pelo docente está sendo questionado, o que não é objetivo do trabalho colaborativo. Ao contrário, essa abordagem representa a busca pela superação do individualismo e da alienação, ainda tão presentes em ambientes escolares (MAGALHÃES; FIDALGO, 2010).

Por se tratar de um trabalho que é construído ao mesmo tempo em que é implementado por docente e pesquisador, sem etapas ou ações rigidamente estabelecidas, a base da pesquisa colaborativa vem se solidificando ao longo dos anos, à medida que vem sendo utilizada em pesquisas, sobretudo, no campo aplicado dos estudos da linguagem. Magalhães e Fidalgo (2010) explicam que essa abordagem de pesquisa passou por vários momentos até chegar à sua organização atual, sendo constantemente aprimorada, como seria natural na base dessa epistemologia.

Inicialmente, o trabalho colaborativo foi tido como sinônimo de cooperação. Um trabalho conjunto que não obrigatoriamente primava pela negociação, mas pela aceitação das ideias de um pelo outro. O questionamento e a crítica instauravam-se como grandes desafios ainda pouco explorados (MAGALHÃES; FIDALGO, 2010). No segundo momento, passou-se a considerar o processo de negociação, levando-se em conta a importância de um paradigma crítico para o trabalho de formação de professores. Foram incorporadas às bases da pesquisa colaborativa as chamadas ações linguísticas mediacionais (MAGALHÃES, 1994), a partir de Smyth (1992), destacando as ações de descrever, informar, confrontar e reconstruir. Porém, uma problemática ainda interferia no processo: por meio das ações críticas, esperava-se do professor a aplicação/reprodução da teoria e da prática discutida (MAGALHÃES; FIDALGO, 2010). Assim, aspectos imprescindíveis do microcosmo eram deixados de lado. Na busca por aprimorar a abordagem colaborativa de pesquisa, o terceiro momento foi marcado pela atenção ao contexto, conteúdo, discurso etc. Segundo Fidalgo (2006), esse avanço na pesquisa colaborativa foi crucial para a identificação dos papeis sociais dos interlocutores.

O quarto e atual momento pelo qual passa essa abordagem de pesquisa ancora-se, sobretudo, em Vygotsky (1930-1978), no tocante à Zona de Desenvolvimento Proximal (ZDP). A colaboração é mais do que nunca vista como um trabalho compartilhado, com foco nas atividades conjuntas e interação no sentido de gerar uma ZDP mútua (MAGALHÃES; FIDALGO, 2010). A transformação das ações 
docentes não é resultado de uma aplicação, mas de colaboração, construção e responsabilidades partilhadas, em que professor e pesquisador aprendem e modificam-se em práticas discursivas. A partir desse panorama histórico elencado pelas pesquisadoras, nota-se que, aos poucos, a pesquisa colaborativa foi tomando forma, sempre em busca de aproximar escola e academia e de efetivar, nas minúcias de cada etapa do processo, a colaboração entre ambas.

Por seu caráter coparticipativo, a pesquisa colaborativa é bastante pertinente para programas de formação continuada de professores, como um meio de se distanciar do estereótipo de muitos programas estatais que apresentam novas teorias ou práticas para serem implementadas pelo docente em sala de aula, sem instruir sobre como isso deve ser feito ou considerar o contexto específico em que o docente está inserido. Como discute Horikawa (2008), o trabalho colaborativo aponta para a latente necessidade de se construírem discursos cada vez mais polifônicos, em que sejam consideradas as vozes sociais trazidas pelos participantes do trabalho educativo. A autora ressalta ainda que, no movimento entre teoria e prática, há sempre a mediação do sujeito e do contexto, que não podem ser desconsiderados. São limites, intenções, possibilidades que permeiam toda a ação docente, impedindo que haja transposição direta da teoria para a prática (HORIKAWA, 2008).

Magalhães salienta que, na pesquisa colaborativa, todo momento é oportuno para "questionar, expandir, recolocar o que foi posto em negociação" (2002, p. 28), o que proporciona, além de produção de conhecimento, desenvolvimento profissional para os envolvidos.

Ao pontuar a pertinência dessa pesquisa no ambiente escolar, Ibiapina (2008, p. 114-115) afirma:

[...] quando o pesquisador aproxima suas preocupações das preocupações dos professores, compreendendo-as por meio da reflexividade crítica, e proporciona condições para que os professores revejam conceitos e práticas; e de outro lado, contempla o campo da prática, quando o pesquisador solicita a colaboração dos docentes para investigar certo objeto de pesquisa, investigando e fazendo avançar a formação docente, esse é um dos desafios colaborativos, responder as necessidades de docentes e os interesses de produção de conhecimentos. A pesquisa colaborativa, portanto, reconcilia duas dimensões da pesquisa em educação, a produção de saberes e a formação continuada de professores. Essa dupla dimensão privilegia pesquisa e formação, fazendo avançar os conhecimentos produzidos na academia e na escola.

Portanto, a relação entre teoria e prática, seus agentes e seu contexto, é fundamental para um trabalho colaborativo efetivo.

Algumas características devem ser atenciosamente atendidas para a legitimidade do processo. Entre elas, destacam-se a participação voluntária, a responsabilidade e a autonomia dos envolvidos. 
Como se trata de um trabalho conjunto, o professor precisa identificar-se com o objeto de estudo e efetivamente desejar aprofundar os conhecimentos sobre ele. Sem a participação voluntária, o trabalho perde seu caráter colaborativo, centrando-se apenas em ações estabelecidas pelo pesquisador. No trabalho de colaboração, não há passividade por nenhuma das partes, o pesquisador não pode ser mero observador, assim como o docente não pode ser um aplicador de etapas que lhe foram estabelecidas (BORTONI-RICARDO, 2011). Outro aspecto pertinente nesse escopo é o engajamento do docente (IBIAPINA, 2008), adquirido como consequência de sua participação volitiva e dos esclarecimentos precisos pelo pesquisador durante todo o processo.

Dada a necessidade de encontros de estudo, chamados de sessões reflexivas (MAGALHÃES, 2002), a responsabilidade do pesquisador e do professor é fundamental tanto na construção do projeto quanto na constante reflexão sobre ele. Embora o nome colaborativo remeta à participação conjunta, na pesquisa colaborativa a autonomia do pesquisador e do professor é bastante considerada, pois o processo requer constante avaliação das práticas e construção de conhecimento, o que pode resultar na necessidade de rever condutas, adequar atividades previstas etc. Ao discutir o movimento entre coparticipação e autonomia, Magalhães elucida: "processo colaborativo não significa que todos os participantes tenham a mesma 'agenda' ou o mesmo poder institucional ou de saber, mas que tenham possibilidades de apresentarem e negociarem representações e valores na compreensão da realidade" (MAGALHÃES, 1998, p. 73). Além disso, a autora destaca que não é uma regra que pesquisador e docente tenham igual poder de decisão durante o processo (MAGALHÃES, 1998), o fundamental é que tudo isso seja precisamente negociado, a fim de que ambas as partes conheçam e ajam eficazmente em seu campo de atuação, cada qual com as atividades que lhe foram conjuntamente designadas. É nesse ponto que se instaura a essência do trabalho colaborativo.

Outra característica é que o pesquisador deve promover os momentos de reflexão por meio de perguntas sobre a prática docente ou visando à assimilação teórica, sempre no sentido de ampliação e compartilhamento do conhecimento e também de aprimoramento das práticas de ensino. As perguntas ajudam a estabelecerem relações entre objetivos pretendidos, ações efetivadas e a teoria (MAGALHÃES; FIDALGO, 2010).

Os momentos constantes de reflexão tornam essa abordagem de pesquisa riquíssima em geração de registros, por isso é necessária à organização de todos eles, utilizando recursos como vinhetas, diários, relatórios, gravações, observação etc. Como ressalta Cabral (2012), esse caminho epistemológico deve seguir uma direção dialética da realidade social, fazendo relações e tomando a 
práxis como mediação primordial para construção de conhecimento. O cuidado com a coleta dos registros auxilia na precisão da análise e também na construção do processo, pois muitas perguntas surgem àquele que está conduzindo o trabalho colaborativo (MAGALHÃES; FIDALGO, 2010).

A partir dos aspectos teóricos apresentados, sistematizam-se as ações que são caras à pesquisa colaborativa:

a) Aproximação academia e escola: busca-se mais do que compreender as problemáticas da escola ou das práticas de sala de aula, levar o docente à compreensão e construção de novas possibilidades para serem incorporadas em suas ações;

b) Negociação e interação: no processo de estudo teórico-metodológico e de construção de conhecimentos, preza-se pela discussão de valores, conceitos e ideias, fazendo com que o trabalho colabore significativamente para ambas as partes. É por meio da interação (BAKHTIN, 2010) que pesquisador e docente percebem quanto e como podem colaborar um com o outro;

c) Responsabilidade e engajamento: a responsabilidade do pesquisador está em ser o condutor de todo o processo. Mesmo em coparticipação, é dele o dever de certificar-se de que as ações estejam sendo sempre negociadas, de garantir um espaço favorável à crítica, aos relatos, à reformulação. A responsabilidade do pesquisador é o ponto de partida para o engajamento pelo docente, que deve se sentir seguro, num processo que muito provavelmente lhe é novo, pois é um trabalho em que há autoavaliação e avaliação conjunta de práticas muitas vezes reproduzidas há anos com seus alunos. Outro ponto relevante é que só há possibilidade de engajamento total do docente se sua participação no trabalho for volitiva. Assim, a colaboração torna-se um encontro de interesses, de questionamentos, que podem ser divergentes, mas que caminham no mesmo sentido no que diz respeito ao objetivo final;

d) Coparticipação e autonomia: a elaboração conjunta dos objetivos, das fases do processo de colaboração, das atividades a serem desenvolvidas em sala são necessárias para a conexão teoria e prática, considerando o encontro de experiências e conhecimentos que pode ser muito positivo. Contudo, as tarefas não precisam ser todas desenvolvidas conjuntamente, podem ser divididas, desde que tudo isso seja anteriormente negociado. Com a divisão de atividades, pesquisador e docente podem exercer sua autonomia no processo, correndo riscos, tomando decisões, reformulando ações previamente construídas que, em 
determinado momento, podem não atender ao contexto imediato. O exercício da autonomia faz com que cada um colabore com aquilo em que tem mais conhecimento. $\mathrm{O}$ pesquisador, por exemplo, pode decidir importantes aspectos referentes aos fundamentos teórico-práticos que nortearão o trabalho, contudo, é o docente o maior conhecedor do contexto escolar e de sua sala de aula;

e) Conexão teoria + prática + sujeito + contexto: ao adquirir novos conhecimentos, não se deve esperar que o professor faça uma transposição direta para a sua prática. As novas informações são, na verdade, incorporadas, somadas a conhecimentos e experiências anteriores. Isso não pode ser desconsiderado. É justamente o não apagamento do sujeito do contexto macro e micro em que está inserido que proporciona a conexão teoria e prática de maneira consistente, com ações que efetivamente possam ser implementadas;

f) Sessões reflexivas: os encontros entre pesquisador e docente podem acontecer durante todo o trabalho de colaboração, é fundamental que isso ocorra para que haja negociação e interação. Esses encontros podem ser para estudo teórico-metodológico, elaboração conjunta de ações ou atividades, discussão sobre o andamento das atividades em desenvolvimentos, avaliação, reavaliação, reformulação de objetivos ou de atividades. Dada sua importância, o ideal é que as sessões reflexivas sejam gravadas, pois costumam ser um rico material para análise da construção e apropriação de novos conhecimentos;

g) Coleta constante de registros: por se tratar de uma abordagem de pesquisa em que as etapas vão sendo construídas à medida que o projeto é desenvolvido, todos os registros podem ser recolhidos, pois se trata de uma construção coparticipativa, colaborando não só para a fase final de análise, mas também para a compreensão do andamento do processo e para tomadas de decisão necessárias durante o processo. Ao final, na fase de análise, pode ser que nem todos os registros sejam pertinentes à discussão e compreensão dos resultados, contudo, isso é algo que só pode ser avaliado ao concluir o trabalho colaborativo. Portanto, diários de campo, gravações, cronogramas, atividades, tudo pode ser cuidadosamente recolhido para, posteriormente, identificar aqueles que serão significativos ao processo de análise.

Em consonância com as características levantadas, Bortoni-Ricardo (2011) apresenta grande colaboração à organização dessa abordagem de pesquisa. Ao defender a pesquisa etnográfica colaborativa para trabalhos com professores em exercício, a pesquisadora elenca as fases pelas quais 
passa um trabalho nessa perspectiva, contribuindo significativamente para o seu desenvolvimento, tendo em vista que vários estudos mencionam as características da pesquisa colaborativa, mas raros oferecem uma alternativa de como pode ser desenvolvido. Listam-se, aqui, os procedimentos propostos pela autora:

1) Perguntas exploratórias: elas orientam o trabalho do pesquisador, que passa a conhecer seu ponto de partida;

2) Observação piloto: esse procedimento serve para conhecer também o ambiente em que a pesquisa será realizada;

3) Definição do objetivo geral e dos objetivos específicos;

4) Asserção geral e subasserções: as asserções são uma forma de estabelecer hipóteses acerca dos resultados do trabalho a ser realizado;

5) Conhecer a realidade/contexto da pesquisa: as "amostras são coletadas via observação participante, entrevistas, material documental recolhido no ambiente da pesquisa ou pelo emprego de recursos tecnológicos, como a gravação em vídeo ou em áudio, fotografias” (BORTONI-RICARDO, 2011, p. 76);

6) Diálogo e interação: na pesquisa colaborativa, a interação deve ser constante. É por meio dela que se compreende e se constroem teorias e práticas. A interação é o cerne do trabalho colaborativo, destacando-se que acima do conteúdo da interação está o modo como ela se dá;

7) Avaliação: este é um procedimento que, assim como a interação, percorre todo desenvolvimento do estudo. Se o objetivo é realizar um trabalho colaborativo, os encontros entre pesquisador e docente devem ser sempre oportunos para a avaliação dos pontos positivos e negativos das ações realizadas;

8) Reorganização/revisão: uma avaliação é profícua se resultar em uma ação. A atitude de revisar objetivos estabelecidos e analisar pontos positivos e negativos pode levar à reformulação de atividades;

9) Registros e ações futuras: em sua proposta, Bortoni-Ricardo (2011) menciona a importância de o pesquisador e o docente produzirem registros individuais sobre o desenvolvimento da pesquisa. Para a autora, eles podem ser subsídio para ações futuras como o compartilhamento dos resultados do trabalho colaborativo com outros professores. 
As etapas propostas não seguem, obrigatoriamente, uma ordem cronológica, pois muitas delas ocorrem do início ao fim do trabalho, porém sua organização de maneira didática contribui para melhor orientação ao pesquisador que se proponha a realizar uma pesquisa colaborativa.

$\mathrm{Na}$ seção de análise, relata-se o trabalho colaborativo realizado, considerando os aspectos imprescindíveis a essa abordagem epistemológica, tomando por base as etapas dispostas nesta seção.

\section{Pesquisa colaborativa na formação docente}

Para desenvolver este trabalho, além de nos ampararmos na proposta colaborativa de pesquisa, buscamos respaldo na teoria dialógica do discurso, no que se refere aos conceitos de interação e responsividade (BAKHTIN, 2010). Bakhtin (2010) postula que os sentidos se constroem por meio da interação entre o locutor e o outro. Nesse processo, locutor e interlocutor ocupam um papel ativo, de negociação, reelaboração etc. $\mathrm{O}$ autor ensina também, que todo discurso que proferimos é sempre permeado por vozes alheias, isto é, tudo o que dizemos carrega consigo outros discursos já ouvidos/lidos, outras experiências vividas, que nos fazem elaborar um discurso ao mesmo tempo plural, mas sempre marcado por idiossincrasias. Ao dirigirmos nosso discurso ao outro, sempre esperamos deste uma resposta. Por isso, todo enunciado exige uma atitude responsiva; ainda que não haja uma reposta/uma contrapalavra verbalizada, o discurso proferido sempre ecoará algo no outro, seja de forma imediata ou tardia, em outras interações dos quais esse outro participar (BAKHTIN, 2010).

Acreditamos que os pressupostos da perspectiva dialógica vêm ao encontro do que propõe a pesquisa colaborativa, no sentido de que se preza pela agentividade, pela coparticipação, pela construção coletiva, mas sempre observando as singularidades do pesquisador, do docente e do contexto.

O objetivo que norteou a pesquisa colaborativa relatada foi a contribuição para o ensinoaprendizagem dos processos de revisão e reescrita a partir de textos narrativos, sobretudo no que concerne ao trabalho docente de corrigir e revisar textos de alunos. A pesquisa foi desenvolvida em uma cidade do noroeste do Paraná com uma professora da Educação Básica e com seus alunos do $4^{\circ} \mathrm{e}$ do $5^{\circ}$ anos do Ensino Fundamental I.

Trata-se de uma pesquisa colaborativa por ter sido construída fundamentalmente pela interação entre pesquisador e docente e entre docente e alunos. A partir de trabalho de estudo teóricometodológico desenvolvido entre pesquisador e docente, as práticas de sala de aula foram sendo 
produzidas e refletidas. Além disso, partiu-se de um ambiente extraescolar, considerando o estudo e a experiência da docente, para se chegar ao ambiente escolar. Mesmo em sala de aula, não deixaram de ser considerados aspectos do contexto mais amplo, como o histórico da prática de escrita dos alunos e a formação acadêmica da docente, assim como suas relações com a escrita. Foram obtidos diversos registros, como gravações em áudio, imagens, produções textuais e outras atividades escritas de alunos, assim como anotações da docente.

Um projeto-piloto desenvolvido no ano anterior (GASPAROTTO; MENEGASSI, 2013) apontou a pertinência do trabalho colaborativo, em maior período de tempo, para oferecer subsídios teórico-metodológicos a um docente e acompanhar o processo de implementação desse estudo em sala de aula. Com a definição do tema e do objetivo norteador da pesquisa, passou-se à fase de contato para identificar um sujeito específico com interesse em integrar o trabalho.

A primeira professora convidada aceitou o convite. A docente, aqui nominada como Ana, e o pesquisador já se conheciam, o que facilitou o contato. Ao saber que se tratava de um trabalho sobre o tema de revisão e reescrita de textos, Ana mostrou-se bastante interessada, alegando ser algo que a instigava muito em sua prática, por isso desejava conhecer sobre o processo. Assim, afirma-se que o fato de ambos se conhecerem e o prévio interesse da docente acerca do tema da pesquisa foram a motivação para sua participação volitiva, marcada do início ao fim do processo.

O contato do pesquisador ocorreu somente com a docente, por meios de sessões reflexivas (MAGALHÃES, 2002), sendo que o trabalho em sala de aula foi todo realizado por Ana sob orientação e acompanhamento externo.

\section{Perguntas exploratórias, observação, contexto, definição de objetivos}

Nos primeiros passos de pesquisa colaborativa, têm-se aqueles que auxiliam no conhecimento pelo pesquisador do seu campo de pesquisa, como perguntas exploratórias, observação e contexto; e aquele que significa o ponto de partida para os estudos: a definição de objetivos. Esses procedimentos foram sendo construídos durante todo o processo, mas foi, sobretudo, no primeiro encontro entre pesquisador e docente que eles foram realizados.

Os encontros, que aconteceram antes, durante e após o desenvolvimento da oficina de produção pela professora em sala de aula, visavam ao estudo, reflexão e orientação da prática da docente e foram todos gravados em áudio. No primeiro encontro, explicou-se mais precisamente o objetivo geral da pesquisa e fizeram-se algumas perguntas exploratórias (BORTONI-RICARDO, 2011) para levantar 
dados sobre o campo e a jornada de trabalho da professora. Assim, ambos os envolvidos poderiam discutir aspectos mais específicos sobre o desenvolvimento do trabalho e chegar ao recorte temático adequado e aos objetivos específicos. Esse primeiro contato apontou, portanto, uma prática coparticipativa para a elaboração do projeto e não apenas para sua implementação. As perguntas exploratórias lançadas pelo pesquisador definiram o contexto de trabalho de Ana:

Em 2012, quando aceitou participar da pesquisa, Ana ministrava aulas de Língua Portuguesa para $4^{\circ}$ e $5^{\circ}$ anos do Ensino Fundamental, no período matutino. Sua carga horária semanal nessa escola era de vinte horas, sendo, em média, oito horas/aula em cada série e as outras quatro destinadas à preparação, chamadas de horas-atividade. Além de ser professora efetiva pelo município, a docente matinha contrato de 40 horas com o governo do estado, ministrando aulas em nível de Ensino Médio para Curso de Formação de Docentes, além de monitorar cursos de formação a distância em plataformas virtuais. Desse modo, sua carga horária semanal, entre sala de aula e horas/atividade era de 60 horas.

Na conversa, Ana manifestou interesse em realizar o trabalho de revisão e reescrita com seus alunos de $4^{\circ}$ e $5^{\circ}$ anos, pois era nessas turmas que tinha mais dificuldade de realizar a reescrita, de compreender como o processo acontecia efetivamente. A escolha de Ana representou um grande desafio à pesquisa. Porém, foi preciso considerar um dos princípios da pesquisa colaborativa, de responder às necessidades docentes e os interesses de produção de conhecimento (IBIAPINA, 2008). Além disso, a escolha contribuiu para reiterar o aspecto coparticipativo dessa abordagem de pesquisa. Foi uma oportunidade para ambos construírem novos conhecimentos.

Após decidir o enfoque do trabalho para o Ensino Fundamental I, passou-se à definição do gênero discursivo norteador da oficina de produção textual. Ana mencionou que naquele semestre precisaria trabalhar narrativas ficcionais com os alunos, optando-se pelo gênero Conto de Terror.

Por fim, o pesquisador salientou a necessidade de organizar um cronograma de atividades e de serem entregues termos de consentimento aos pais de alunos, à docente e à Secretaria da Educação do município, a fim de que se obtivesse autorização para utilização dos registros. Essas duas tarefas ficaram sob a responsabilidade do pesquisador, sendo que o cronograma seria levado ao próximo encontro para discussão conjunta. A entrega e a coleta de assinaturas dos termos de consentimento dos pais ficaram sob responsabilidade da docente. Como se nota, dede o primeiro encontro a negociação entre pesquisador e docente levou à divisão de tarefas (MAGALHÃES, 1998), considerando-se os aspectos como a jornada de trabalho de Ana. 


\section{Diálogo e interação}

Assim, como as etapas anteriores, o diálogo e a interação (BAKHTIN, 2010), obrigatoriamente, permearam todo o desenvolvimento da pesquisa. Contudo, a partir do segundo encontro, quando se iniciaram as sessões de estudo, é que foram realizadas várias trocas de experiências e discussões acerca dos textos estudados, no sentido de levar a proposta mais adequada aos alunos de Ana.

No início do segundo encontro, o pesquisador apresentou à docente a proposta de organização das atividades, destacando que poderia haver alterações necessárias durante o processo, mas que seria importante tomá-la como base para melhor organização de ambos. Como explica Magalhães (2008), no trabalho colaborativo não significa que todos tenham o mesmo poder de decisão, desde que isso seja negociado entre os pares. Aqui, a medida do pesquisador ao chamar a atenção para o cumprimento do cronograma não visou à imposição sobre a docente. Na verdade, elucida-se a responsabilidade necessária ao trabalho colaborativo, pois é do pesquisador a função de dirigir e garantir que o trabalho tenha um bom andamento. Ademais, ainda que se trate de um trabalho que toma forma enquanto é produzido, é preciso prezar por aspectos essências à seriedade da pesquisa. Não se pode confundir coparticipação com descuido aos procedimentos de pesquisa.

O cronograma de execução foi elaborado com base nos horários de disponibilidade da professora, considerando a divergência de agendas entre pesquisador e docente, como pontua Magalhães (1998). As atividades foram realizadas entre os dias 14 de julho e 11 de dezembro do ano de 2012 e consistiram basicamente em três etapas: a) encontros colaborativos de estudos teóricometodológicos e elaboração de oficina de produção textual com a professora; b) desenvolvimento da oficina de produção textual em sala de aula e encontros paralelos de orientação com o pesquisador; c) organização e lançamento da coletânea de textos com os alunos.

Primeiramente houve um período de estudo e discussão da teoria e da metodologia acerca dos processos de revisão e de reescrita, depois passou-se à construção e desenvolvimento das atividades com os alunos e, ao final, como sugestão da docente, foi elaborada uma coletânea de textos, em forma de livreto, que serviu para motivar os alunos durante todo o trabalho com a escrita naquele semestre. Essas três etapas são apresentadas inseridas nas fases da pesquisa colaborativa propostas por BortoniRicardo (2011). 


\section{Estudo teórico-metodológico e elaboração da oficina de produção textual}

Para a realização dos encontros de estudo teórico-metodológico, o pesquisador selecionou textos para leitura e estudo com a docente. Foram quatro textos de diferentes autores com pesquisas no campo aplicado dos estudos da linguagem escrita que tratavam dos temas, respectivamente: concepções de escrita; dialogismo e interação; processo de revisão e reescrita de textos; alternativas metodológicas para revisão docente em textos de alunos.

Por considerar a densa carga horária de trabalho da professora, optou-se por não realizar encontros ao final da leitura de cada texto, pois o trabalho poderia se tornar inviável. Assim, organizouse o material, de modo a dialogar com a professora. Para cada texto, foi redigido um texto de apresentação, informando sua referência e temática abordada, e também roteiros de leitura, em forma de perguntas orientadoras, que foram apresentadas ao final de cada texto, com a finalidade de promover a reflexão sobre o texto lido e a possibilidade de relacioná-lo com a prática da professora. Além disso, em alguns textos, foram oferecidas perguntas exploratórias, a fim de conhecer as práticas efetivadas pela docente em sala de aula e sua relação com sua formação acadêmica.

Bortoni-Ricardo (2011) destaca a importância da realização de um estudo teórico-prático, concebido neste espaço como teórico-metodológico, a fim subsidiar a compreensão da realidade e a construção de novas práticas. A elaboração dos roteiros de leitura junto à seleção dos textos foi fundamental para a manutenção da colaboração no período de leitura em que não houve encontros com a docente. Os roteiros também serviram para mediação por meio da práxis, como propõe Cabral (2012), pois os questionamentos sempre traziam à discussão elementos da experiência e da prática de Ana.

Após a entrega do material para a professora, o pesquisador perguntou sua opinião sobre a quantidade de leituras e o tempo reservado para esse estudo, com o intuito de saber se ela havia considerado os estudos muito densos. Em conversa gravada em áudio, a docente respondeu: "Não, não... Na verdade é, mas eu quero. Então, essa é a diferença: eu quero, tá. Então, fica tranquila que eu estou fazendo o que eu gosto". Na fala da docente, é notável sua participação volitiva e seu engajamento (IBIAPINA, 2008).

Durante o período de estudo do material, manteve-se contato com a professora Ana apenas por e-mail, perguntando como estava o processo de leituras e resolvendo questões referentes aos termos de consentimento. Na sequência, apresenta-se uma das conversas trocadas, por e-mail, nesse período. 
Do pesquisador para Ana, no dia 6 de agosto de 2012:

Oi Ana, tudo bem?

Eu deixei os livros com você, mas só depois me lembrei de que vou precisar tirar outra cópia para arquivar. Neste fim de semana estarei aí e te procuro para pegar.

E como estão as leituras?

Deu certo de a diretora assinar o termo de consentimento?

Abraço, boa semana.

Resposta de Ana, no dia 6 de agosto de 2012:

Olá,

Tudo ótimo, estou na segunda leitura. Esta semana estou em Foz do Iguaçu em um simpósio, chego na sexta-feira, podemos conversar no sábado, não terei pós. A Diretora assinou o termo, te entrego ele e os livros no sábado.

Até lá!

Além do período de estudo, durante todo o processo, quando não havia possibilidade de encontros, houve troca de e-mails, com o intuito de compartilhar informações sobre o andamento das atividades, sanar dúvidas, enviar materiais etc. Todos os e-mails foram arquivados como registros de pesquisa.

O terceiro encontro com Ana ocorreu no último dia do mês de agosto, retomaram cada texto lido durante o mês, discutindo-se a proposta de cada um deles, considerando-se os questionamentos iniciais e os roteiros de leitura elaborados para cada texto. Apesar de as perguntas terem sido formuladas apenas para reflexão e discussão oral, Ana preferiu respondê-las por escrito, assim que terminava a leitura de cada texto. Suas anotações serviram de base para a abordagem e a discussão dos textos nesse encontro.

A decisão de Ana por escrever suas respostas parece ter sido a de estar mais preparada para o encontro de estudo. Na conversa, mesmo lendo o que havia escrito após cada questionamento, a docente completava com comentários explicativos e sempre deixava o espaço aberto para a discussão (MAGALHÃES; FIDALGO, 2010). Na visão do pesquisador, essa atitude não revelou insegurança por parte da docente, mas, sim, comprometimento com o estudo. Ana alegou, na gravação desse encontro, que preferiu fazer anotações assim que lia os textos, porque as leituras foram feitas em dias diferentes.

Para melhor compreensão sobre como as perguntas do roteiro de leitura orientaram as sessões de estudo, apresenta-se um exemplo. No material, o quarto texto discutia propostas metodológicas de revisão docente em textos de alunos, isto é, como o professor procederia à correção do texto. $\mathrm{Na}$ apresentação do texto, antes da leitura pela docente foram oferecidas perguntas exploratórias, como: 
Qual é sua maior dificuldade ao corrigir os textos de seus alunos?

Como você costuma corrigir os textos de seus alunos?

Após a leitura do texto, com a docente tendo observado diversas maneiras de auxiliar o aluno na reescrita de textos, via revisão, propuseram-se os seguintes questionamentos:

A partir dessa leitura, há alguma medida que você não utiliza e que gostaria de adotar em sua prática em sala de aula?

Tomando por base todas as etapas de leitura que seguimos, você faria alguma ressalva? Levantaria algo que não foi e que deveria ter sido comentado, ou que foi comentado, mas você não concordou?

Os questionamentos anteriores à leitura levaram à reflexão da docente sobre sua própria prática. Ainda não se propunha nenhuma mudança, mas as perguntas ajudaram no reconhecimento de práticas já estabelecidas no cotidiano que talvez, há muito, não haviam sido repensadas. Essas informações também contribuíram para que se percebesse o que já era de conhecimento da docente e como seria possível contribuir com sua formação por meio do estudo teórico-metodológico. Assim, atende-se à proposta de Magalhães e Fidalgo (2010), para as quais a pesquisa colaborativa não desconsidera o conhecimento docente, mas visa reconstruir conhecimentos para contribuir com melhorias na realidade escolar. Trata-se de uma incorporação de conhecimentos e práticas e não de uma reprodução.

Ao final, as questões que procedem à leitura do texto já propõem uma conexão entre teoria e prática. Ao retomar o que aponta Horikawa (2008), no que concerne à consideração do sujeito e do contexto em que ele se insere, o pesquisador propõe uma relação dos textos lidos com a prática docente. É preciso reforçar que as metodologias de revisão docente apresentadas são propostas de pesquisadores e não receitas a serem religiosamente seguidas e, talvez, este seja um dos grandes desafios da atualidade: levar à escola o aprofundamento de teorias e sugestões metodológicas, com o intuito de promover a reflexão sobre as práticas de ensino e não de oferecer soluções genéricas aos problemas de escrita, por exemplo.

A reflexão sobre os textos trabalhados levou às seguintes compreensões:

- Todo o material teórico convergia para o enfoque na concepção de escrita como trabalho (MENEGASSI, 2010), cujos princípios consideram desde a elaboração de um comando de produção textual, passando pela reescrita do texto pelo aluno, até que fique adequado à proposta de produção;

- A experiência da professora como aluna traz um bom histórico de produções textuais, porém voltadas à concepção de escrita como consequência (MENEGASSI, 2010); 
- Entre as dificuldades encontradas pela docente ao corrigir os textos de seus alunos está, em ordem de relevância, o pouco conhecimento sobre como proceder à revisão, o curto tempo e o elevado número de alunos por sala;

- A docente realizava correções resolutivas nos textos de seus alunos, enfocando aspectos de ortografia e acentuação. Não eram contemplados em sua revisão aspectos concernentes ao conteúdo do texto ou à estrutura do gênero discursivo trabalhado;

- As respostas escritas e orais da docente aos roteiros de leitura mostraram compreensão adequada dos textos estudados, como: condições de produção, interlocutor, gênero discursivo, revisão, reescrita;

- Com as leituras, a professora reconhece que sua prática de sala de aula com a escrita atinha-se à higienização do texto e afirma que considera a revisão necessária em todos os níveis de aprendizagem.

Após a leitura dos textos, uma das falas da professora no encontro de estudo foi:

[...] Essa questão da reescrita... Eu confesso que eu nunca consegui trabalhar reescrita. Na verdade, ainda está incutido de que a produção é o produto final do trabalho e ponto final [...]. E aí conforme eu fui lendo os textos eu até acreditava que eu fazia reescrita, mas não era reescrita que eu fazia. Era apontamento, higienização, não é reescrita [...] E aí você começa a perceber que, apesar de, porque eu tô com Língua Portuguesa já há sete oito anos só com Língua Portuguesa. E eu não faço reescrita, eu faço higienização, faço correção de erros ortográficos, eu não faço reescrita.

O reconhecimento da necessidade de transformação da realidade encontrada (BORTONIRICARDO, 2011) revela-se um grande aliado para o sucesso do trabalho colaborativo em questão.

Ao final desse estudo, foram digitalizadas todas as páginas dos textos que continham anotações da docente. Esse recurso foi utilizado porque o material apresentava perguntas para discussão, as quais foram todas respondidas por escrito por opção da própria professora.

Após a retomada dos textos, passou-se a atentar para o trabalho de revisão docente. A fim de mostrar como poderiam ser feitos comentários de revisão, o pesquisador levou textos de alunos de $5^{\circ}$ ano, já corrigidos pela professora da turma. Os textos foram utilizados para que se analisassem os comentários de revisão feitos pelo professor e a sua consideração pelo aluno na reescrita. Essa foi mais uma medida para subsidiar a prática docente.

O quarto encontro, já na segunda quinzena de setembro, foi dedicado à elaboração da oficina de produção textual a ser desenvolvida com os alunos. Pesquisador e docente recolheram material durante 
o período de estudo teórico-metodológico e, naquele dia, juntaram suas ideias, propostas e construíram juntos uma oficina de produção textual, enfocando o Conto de Terror, que culminaria em duas produções textuais por cada aluno, todas passando pelo processo de revisão e reescrita.

Após prepararem a primeira parte da oficina, decidiram esperar o desenvolvimento em sala dessa primeira etapa, que se encerrava com a primeira produção escrita, para só então formular a sequência da oficina, que culminaria na segunda produção escrita. Essa medida foi tomada para que o trabalho fosse avaliado em seu processo e reformulações pudessem ser feitas, quando necessárias, conforme orientações da pesquisa colaborativa.

\section{Avaliação, reorganização, revisão}

O período de trabalho em que predominaram as avaliações, negociações, revisões etc. foi durante o desenvolvimento da unidade de ensino pela professora Ana com os alunos. Como as atividades de sala de aula ficaram sob responsabilidade dela, os e-mails e os encontros de orientação com o pesquisador eram sempre momentos oportunos para relatar, questionar, pois aquele era efetivamente o encontro da teoria com a prática na realidade da docente. Por isso, como orienta Magalhães (2002), prezou-se para que os encontros fossem sempre abertos à discussão, reavaliação, pois aquele seria o momento de maior colaboração da docente. Melhor conhecedora de seu contexto de trabalho, foi Ana quem teve naquele momento maior poder de decisão.

No período de desenvolvimento, em sala de aula, das atividades e produções de textos, com acompanhamento da docente, todo material produzido pelos alunos foi recolhido. As produções textuais e as versões reescritas foram digitalizadas pela pesquisadora e salvas em pastas individuais com o nome de cada aluno. Esse material foi fundamental para análise dos comentários de revisão da professora e da progressão dos alunos em suas diversas produções. A medida atendeu ao que propõem Magalhães e Fidalgo (2010) no tocante ao cuidado com a geração de registros, alertando que, além de conduzirem toda a análise, eles podem ser consultados durante o desenvolvimento do trabalho já que, na pesquisa colaborativa, muitas questões podem surgir ao pesquisador.

Nos encontros, concomitantes ao desenvolvimento da oficina de produção textual, houve vários momentos de negociação e reavaliação de atividades previstas. Neles, a autonomia de Ana recebeu especial destaque. Suas tomadas de atitude mostraram o engajamento e a segurança com que estava conduzindo o processo. Nos tópicos a seguir, relatam-se os principais eventos de negociação e reavaliação entre docente e pesquisador, nos quais a autonomia de Ana foi fundamental: 
a) Na proposta inicial da oficina, previa-se, a partir de atividades acerca da leitura de um conto da escritora Ângela Lago, o desenvolvimento da primeira produção de Conto de Terror. Após a produção, os textos seriam revisados pela professora e, em outra aula, haveria um momento para a reescrita individual pelos alunos. Contudo, a professora explicou que, antes de encaminhar os textos para a reescrita individual, decidiu fazer uma atividade de reescrita coletiva em que projetou um dos textos no quadro e instigou os alunos a perceberem o que precisaria ser corrigido ou melhorado. Essa atividade não havia sido prevista, pois foi no processo de mediação que Ana percebeu que os alunos não estavam preparados para uma reescrita individual, já que essa não era uma prática à qual estavam habituados;

b) Ao mostrar as primeiras produções e reescritas ao pesquisador, a docente relatou que percebeu muita dificuldade dos alunos com relação à pontuação, argumentando que isso precisaria ser trabalhado antes da segunda produção de texto. Assim, o encaminhamento das atividades seguintes foi reavaliado para que fosse realizada essa intervenção. A professora ficou responsável por fazer a abordagem de elementos da pontuação no texto narrativo na semana seguinte e junto ao pesquisador foi elaborada a sequência da oficina de produção textual;

Em dia posterior a esse encontro, enviou-se um e-mail à professora, reforçando as orientações a respeito da revisão, especialmente no tocante à revisão de textos narrativos e às especificidades do Conto de Terror. Esse encaminhamento foi realizado com objetivo de chamar a atenção da docente para aspectos de revisão que ainda não faziam parte de sua prática. $\mathrm{O}$ e-mail com orientações, retomando a teoria e a metodologia estudadas, funcionou como um recurso de manutenção da interação entre pesquisador e docente e reforçou a responsabilidade na divisão de tarefas por ambos. Enquanto a docente observava atentamente aspectos do seu contexto de trabalho, propondo reformulações ou adequações, o pesquisador atentava para que os conceitos teórico-práticos fossem trazidos para as negociações, subsidiando o trabalho colaborativo.

c) Outra atividade prevista que teve que ser repensada a partir do desenvolvimento da oficina de produção textual pela docente foi a realização da segunda reescrita. Ao organizarem as atividades, o pesquisador propôs que, após a primeira reescrita, se os textos ainda apresentassem problemas significativos, a docente faria nova revisão e proporcionaria um momento para que o aluno reescrevesse seu texto pela segunda vez. A intenção era a de que os alunos percebessem a provisoriedade de seu texto e como ele poderia ser melhorado a cada revisão. Porém, novamente trazendo o contexto para o a discussão, Ana considerou que levar os 
alunos a reescrever pela segunda vez o mesmo texto poderia desmotivá-los para a próxima produção. Segundo ela, tratava-se de uma prática nova para os alunos e retomar várias vezes o mesmo texto não seria viável no momento. Ana explicou também que, antes de entregar o segundo texto para os alunos reescreverem, faria uma nova atividade de reescrita coletiva. Essas decisões foram tomadas a partir de sua observação em sala e, em todas, não houve intervenção.

Como se nota, as ações de negociação e avaliação entre a professora e o pesquisador foram marcadas pela autonomia da docente. O processo mostra uma alteridade de vozes (BAKHTIN, 2010) que fundamenta o trabalho colaborativo. No momento de estudo teórico-metodológico, era o pesquisador que trazia novas propostas, novos desafios, portanto, concentrava-se nele o maior poder de decisão. Já no período de implementação das atividades em sala, a experiência da docente com crianças sobrepôs-se à do pesquisador. Assim, era de Ana a voz a ser mais ouvida, era a sua prática que orientava a direção a ser seguida. Essa alternância organizada dos papéis retoma o que propõe Horikawa (2008), ao alertar sobre a necessidade de discurso cada vez mais polifônicos em pesquisas como esta. Sobre o contexto escolar e sua interação com a academia, este pode ser um caminho viável para a superação do individualismo e da alienação (MAGALHÃES; FIDALGO, 2010).

\section{Registros e ações futuras}

Como encerramento do projeto, ao final do semestre, organizou-se uma coletânea de textos, contendo um conto de cada aluno. Desde o início da oficina, os alunos haviam sido comunicados que seus textos comporiam um livro. A organização da coletânea foi uma sugestão de Ana, para motivar os alunos à produção escrita. Foram recolhidos como registros exemplares da coletânea produzida, fotos e filmagem da manhã de lançamento da coletânea, que contou com a presença dos pais. Na organização da coletânea e do evento, a professora ficou responsável pela escolha dos textos junto aos alunos, pela decoração do local e pelo concurso entre os alunos de melhor ilustração de capa e melhor título para a coletânea. O pesquisador elaborou os convites aos pais, fez a diagramação e a impressão da coletânea.

Na manhã do evento, a professora relatou a experiência aos pais e elucidou a importância de esta pesquisa ter chegado até a sua sala de aula:

Eu, sinceramente, acredito que a Educação vai ser muito melhor quando as pessoas que se dedicam ao estudo científico tiverem a preocupação de trazer esse estudo pra prática de sala se aula. Eu sinceramente acredito nisso, que a Educação precisa de pessoas [...] que estão dispostas a estudar, aprofundar o conhecimento teóricocientífico, mas com a preocupação de que esse conhecimento seja usado aqui, em sala de aula, com os nossos alunos. 
A fala de Ana, mesmo não tendo estudado sobre a teoria do trabalho colaborativo com a pesquisadora, vai ao encontro do princípio norteador dessa abordagem de pesquisa: a aproximação entre academia e escola a fim de colaborar com a formação contínua do professor para a transformação da realidade por meio da ação e da reflexão (BORTONI-RICARDO, 2011). O discurso da professora também aponta que sua compreensão foi além da teoria e da metodologia estudadas, pois reconhece a relevância de todo o processo colaborativo, contando como foi significativo ter essa contribuição em sua prática.

\section{Pesquisa colaborativa na formação docente: síntese do trabalho}

Ao considerar os procedimentos do trabalho colaborativo, esta pesquisa apresentou, cronologicamente, as seguintes etapas, a partir dos pressupostos da pesquisa colaborativa:

1) Contato com a docente e sua adesão voluntária;

2) Apresentação do tema de pesquisa e discussão colaborativa sobre seu desenvolvimento;

3) Definição das turmas que iriam participar do projeto ( $4^{\circ}$ e $5^{\circ}$ anos do Ensino Fundamental) e do gênero discursivo que nortearia a prática, em sala de aula;

4) Estudo de conjunto de textos organizado sobre o tema;

5) Discussão e reflexão sobre a teoria e a metodologia estudadas por meio de encontros entre pesquisador e docente, com uso de roteiros de leitura elaborados pelo pesquisador, com o intuito de proporcionar discussão entre o conhecimento assimilado e a prática docente;

6) Encontros para elaboração conjunta de oficina de produção textual a ser desenvolvida com os alunos participantes;

7) Desenvolvimento da oficina de produção textual pela docente, em sala de aula, na qual se inserem os processos de revisão docente e reescrita dos alunos;

8) Encontros de orientação e reflexão, enquanto se executava a oficina, entre pesquisador e docente, sobre o desenvolvimento e a efetividade do trabalho, com enfoque para a relação teórico-prática da revisão docente, atentando-se às necessidades de adaptação ou reformulação das ações previstas conforme a atitude responsiva dos alunos (BAKHTIN, 2010);

9) Organização e produção colaborativa (pesquisador, professora e alunos) de coletânea com os textos produzidos durante o desenvolvimento da oficina de produção e após trabalho de revisão e reescrita;

10) Avaliação e reflexão sobre o trabalho colaborativo ao fim das atividades previstas. 
Esses passos demonstram a efetiva condução de uma pesquisa colaborativa do campo aplicado dos estudos da linguagem na formação docente.

\section{Considerações finais}

O trabalho atendeu ao objetivo de sistematizar os aspectos sobre as características e as etapas da pesquisa colaborativa a partir de discussões de pesquisadores brasileiros, tendo como parâmetro pesquisa conduzida com uma professora de Língua Portuguesa. Evidenciou-se a efetividade do trabalho colaborativo para contribuir com a formação docente e com os processos de ensino-aprendizagem.

$\mathrm{Na}$ experiência de pesquisa colaborativa relatada, a contribuição do pesquisador por meio do subsídio teórico-metodológico, a ampla experiência com ensino de língua materna pela docente e os encontros de compartilhamento e reflexão sobre o tema foram os pilares desta pesquisa. Mesmo com o cronograma de trabalho elaborado em conjunto, as ações foram constantemente avaliadas e reformuladas. Nesse aspecto, a autonomia da docente recebeu destaque, ao lidar com as novas práticas motivadas pelo aprofundamento no estudo teórico-metodológico. Mais uma vez, o contexto da pesquisa, isto é, a situação real de ação docente, foi dando forma a ações que haviam sido colaborativamente pensadas. Não houve, assim, investigação do pesquisador sobre sua própria prática docente, mas um trabalho colaborativo deste com uma docente em exercício.

A pesquisa atendeu às fases da pesquisa colaborativa propostas por Bortoni-Ricardo (2011), elucidando como elas podem ser organizadas e desenvolvidas:

a) Perguntas exploratórias: após o contato e o convite à docente, foram feitos encontros de estudo teórico-metodológico entre pesquisador e docente. A partir dos textos teóricos lidos por ambas, o pesquisador elaborou previamente um roteiro de leitura antes e após cada texto. Esses roteiros, além de apresentar e discutir sobre os textos, continham perguntas que questionavam a docente sobre suas experiências com a escrita e sobre suas práticas de ensino. As respostas serviram para que ambos pudessem relacionar a teoria estudada com a prática e também para que o pesquisador percebesse o conhecimento e a prática da docente e a forma como poderia colaborar com seu desenvolvimento;

b) Observação piloto: como na pesquisa o objetivo centrou-se no trabalho colaborativo com a docente, não houve observação do pesquisador em sala de aula. Todas as atividades em sala 
foram dirigidas pela professora, que manteve contato constante com o pesquisador para compartilhar as condutas observadas;

c) Definição do objetivo geral e dos objetivos específicos: além do objetivo norteador da pesquisa que era compreender como o trabalho colaborativo teórico-metodológico contribui com o ensino-aprendizagem de revisão e reescrita de textos narrativos, foram discutidos, nos encontros, os objetivos específicos a serem almejados com os alunos, no sentido de contribuir efetivamente para o aprimoramento de suas práticas discursivas;

d) Asserção geral e subasserções: as asserções não foram previamente estabelecidas, mas construídas com o desenvolver das atividades;

e) Conhecer a realidade e o contexto da pesquisa: os registros gerados tiveram especial atenção no presente estudo, sendo coletados colaborativamente por pesquisador e docente. Foram gerados áudios dos encontros de estudo teórico-metodológico, anotações da docente, cronograma e todo material produzido pelos alunos;

f) Diálogo e interação: foram preconizadas e analisadas as interações tanto entre pesquisador e a docente como da docente com seus alunos. A primeira foi observada pela gravação em áudio dos encontros de estudo e a segunda foi analisada por meio das produções textuais e da revisão docente nos textos de seus alunos;

g) Avaliação: a realização da oficina de produção textual e a resposta dos alunos por meio de suas produções permitiram avaliar condutas e fazer asserções que não haviam sido consideradas anteriormente. A avaliação leva a outro elemento importante, a reorganização;

h) Reorganização e revisão: o trabalho de revisão e organização foi marcado por conduta significativamente ativa da docente. Pelo fato de conhecer melhor a realidade de trabalho com seus alunos, a professora teve autonomia para fazer adequações nas atividades que haviam sido colaborativamente preparadas. Sua conduta de constante avaliação e revisão do plano de ação reforçou sua atenção e interesse pelo objetivo do trabalho que estava realizando com seus alunos.

Dessa forma, este estudo contribui para a compreensão de como se efetiva a pesquisa colaborativa em situação de trabalho com a linguagem escrita na formação docente e sua importância para a aproximação entre academia e escola. 
Notas

${ }^{1}$ Resultados parciais do Projeto de Pesquisa "Escrita e a formação de educadores de língua", financiado pela Fundação Araucária do Paraná. Uma versão preliminar deste estudo foi apresentada no $4^{\circ}$ Colóquio Internacional de Estudos Linguísticos e Literários.

\section{REFERÊNCIAS}

ANDRÉ, M. E. D. A. Etnografia na prática escolar. Campinas: Papirus, 1995.

ANDRÉ, M. E. D. A. Avanços no conhecimento etnográfico da escola. In: FAZENDA, I. C. A. (Org.). A pesquisa em educação e as transformações do conhecimento. 2. ed. Campinas: Papirus, 1997.

ANDRÉ, M. E. D. A. A pesquisa no cotidiano escolar. In: FAZENDA, I. C. A. (Org.). Metodologia da pesquisa educacional. 6. ed. São Paulo: Cortez, 2000.

BAKHTIN, M. M. Estética da criação verbal. 4. ed. São Paulo: Martins Fontes, 2009.

BAKHTIN, M. M. Marxismo e Filosofia da Linguagem. 12. ed. São Paulo: Hucitec, 2010.

BORTONI-RICARDO, S. M. O professor pesquisador: introdução à pesquisa qualitativa. 2. ed. São Paulo: Parábola, 2011.

CABRAL, M. B. L. Formação docente e pesquisa colaborativa: orientações teóricas e reflexões práticas. 2012. In: SEMINÁRIO REGIONAL DE POLÍTICA E ADMINISTRAÇÃO DA EDUCAÇÃO DO NORDESTE/ENCONTRO ESTADUAL DE POLÍTICA E ADMINISTRAÇÃO DA EDUCAÇÃO, 7; SIMPÓSIO: GESTÃO DA EDUCAÇÃO, CURRÍCULO E INOVAÇÃO PEDAGÓGICA, 2., 2012, Recife. Anais... Recife: Anpae, 2012. Disponível em: $<$ http://www.anpae.org.br/seminario/ANPAE2012/4_formacao.html>. Acesso em 2 set. 2014.

GASPAROTTO, D. M.; MENEGASSI, R. J. A mediação do professor na revisão e reescrita de textos de aluno de Ensino Médio. Revista Calidoscópio, São Leopoldo, v. 11, n. 1, p. 29-43, jan./abr. 2013.

HORIKAWA, A. Y. Pesquisa Colaborativa: uma construção compartilhada de instrumentos. Revista Intercâmbio, São Paulo, v. 18, p. 22-42, 2008.

IBIAPINA, I. M. L. Pesquisa Colaborativa: investigação, formação e produção de conhecimentos. Brasília: Líber Livro Editora. 2008. v. 1.

LÜDKE, M; ANDRÉ, M. E. D. A. Pesquisa em Educação: abordagens qualitativas. São Paulo: EPU, 1986.

MAGALHÃES, M. C. C. An understanding of classrooms interactions for literacy development. In: MERCER, N.; COLL, C. (Ed.). Teaching, Learning and interaction. Madrid: Infancia y Aprendizaje, 1994. 
MAGALHÃES, M. C. C. Projetos de formação contínua de educadores para uma prática crítica. The ESPecialist, v. 19, n. 2, p. 169-184, 1998.

MAGALHÃES, M. C. C. Sessões reflexivas como uma ferramenta aos professores para compreensão crítica das ações da sala de aula. In: CONGRESSO DA SOCIEDADE INTERNACIONAL PARA A PESQUISA CULTURAL E TEORIA DA ATIVIDADE, 5., 2012, Amsterdam. Anais.. Amsterdam: VrijeUniversity, 2002. p. 18-22.

MAGALHÃES, M. C. C.; FIDALGO, S. S. Critical Collaborative research: focus on meaning of collaboration and on mediational tools. Revista Brasileira de Linguística Aplicada, v. 10, n. 3, p. 773797, 2010.

MENEGASSI, R. J. O processo de produção textual. In: SANTOS, A. R. dos; GRECO, E. A.; GUIMARÃES, T. B. (Org.). A produção textual e o ensino. Maringá/PR: Eduem, 2010. p. 75-102. (Formação de Professores em Letras - EAD, n. 6).

OLIVEIRA, C. L. Um apanhado teórico-conceitual sobre a pesquisa qualitativa: tipos, técnicas e características. Revista Travessias, Cascavel, v. 2, n. 3, p. 12-13, 2008.

SMYTH, J. Teachers work and the politics of reflection. American Educational Research Journal, v. 29, n. 2, p. 267-300, 1992.

VYGOTSKY. L. S. Mind in Society. Cambridge, Massachusetts: Harvard University Press, 1978. 


\section{Collaborative research aspects in teacher training}

\begin{abstract}
This study discusses the concept of collaborative research in written language applied studies' field, based on Brazilian researches about this subject (MAGALHÃES, 1994, 1998, 2002; MAGALHÃES; FIDALGO, 2010; IBIAPINA, 2008; CABRAL, 2012; HORIKAWA, 2008; BORTONI-RICARDO, 2011). We aimed to understand and systematize this research's approach characteristics and steps. Starting from a collaborative research fulfilled with a Portuguese language teacher, about the revision and rewriting processes, grounded on dialogic assumptions (BAKHTIN, 2010), we have analyzed the practical application of the identified characteristics and steps, presenting alternatives for a collaborative work development. The results showed this research's approach importance for teacher training and for teaching and learning processes, highlighting the necessary engenderment among academy, school, theory, methodology, subject and context in theoretical methodological researches orientation.
\end{abstract}

Key words: Collaborative research. Teacher training. Revision and rewriting.

\section{Aspectos de la investigación colaborativa en la formación docente}

\section{Resumen}

Este artículo discute el concepto de investigación colaborativa en el campo aplicado de los estudios del lengauge escrito, a partir de investigaciones brasileñas sobre el tema (MAGALHÃES, 1994, 1998, 2002; MAGALHÃES; FIDALGO, 2010; IBIAPINA, 2008; CABRAL, 2012; HORIKAWA, 2008; BORTONI-RICARDO， 2011). Nuestro objetivo comprender y sistematizar las características de este enfoque de investigación y los pasos que lo componem. A partir de una investigación colaborativa hecha com una docente de Lengua Portuguesa, sobre los procesos de revisión y reescritura, de acuerdo con las premisas dialógicas (BAKHTIN, 2010), analisamos la aplicación práctica de las características y pasos levantados, presentando alternativas para el desarollo de um trabajo colaborativo. Los resultados mostraron la importancia de este enfoque de investigación para la formación de profesores e para los procesos de enseñanza- aprendizaje, destacando el engendramiento necesario ente academia, escuela, teoría, metodología, práctica, sujeto y contexto, en la orientación de investigaciones de carácter teórico y metodológico.

Palabras clave: Investigación colaborativa. Formación de profesores. Revisión y reescritura.

Enviado em: 5/7/2015

Aprovado em: 6/10/2016
Denise Moreira Gasparotto

E-mail: denisegasparotto@yahoo.com.br

\section{Renilson José Menegassi}

E-mail: renilson@wnet.com.br 